\title{
Beneficial use of hyperbaric process conditions for welding of aluminium and copper alloys
}

\author{
K. Treutler ${ }^{1,2}$ (D) S. Brechelt ${ }^{1} \cdot$ H. Wiche ${ }^{1,2} \cdot$ V. Wesling ${ }^{2}$ \\ Received: 17 August 2020 / Accepted: 29 January 2021 / Published online: 27 February 2021 \\ (C) The Author(s) 2021
}

\begin{abstract}
The joining of components with as few weld layers as possible is an important aspect of weld seam design due to the resulting reduced manufacturing effort and reduced influence of thermal cycles on the base material as well as reduced distortion. For materials with good thermal conductivity, this is not easily possible. The energy density of the arc has been found to be the core parameter for determining the penetration. In the present work, it is shown how the use of a hyperbaric process environment ( 2 to 16 bar) allows an increase of the energy density of the arc and thus an increase of the penetration depth for selected aluminium and copper alloys. Furthermore, the effects of this novel approach on weld metal metallurgy are presented. It is shown that the penetration depth can be doubled by increasing the ambient pressure. Furthermore, a statistical model for the prediction of the penetration depth depending on the welding parameters will be presented.
\end{abstract}

Keywords Aluminium $\cdot$ Copper $\cdot$ Joining $\cdot$ Hyperbaric process $\cdot$ Microstructure $\cdot$ Penetration $\cdot$ GMA-welding

\section{Introduction}

Gas metal arc welding under an increased ambient pressure is a common practice for repair welding of offshore steel construction under water [1-5]. A transfer of this procedure into a dry hyperbaric joining process offers far-reaching advantages such as shortening the arc length, increasing the energy density and increasing the penetration depth $[3,6]$. Detailed studies on the positive influence of a hyperbaric process

Recommended for publication by Commission IX - Behaviour of Metals Subjected to Welding

K. Treutler

treutler@isaf.tu-clausthal.de

S. Brechelt

office@ isaf.tu-clausthal.de

H. Wiche

office@ isaf.tu-clausthal.de

V. Wesling

office@isaf.tu-clausthal.de

1 Centre for Material Technology, Clausthal University of Technology, Agricloastr. 2, 38678 Clausthal-Zellerfeld, Germany

2 Institute for Welding and Machining, Clausthal University of Technology, Agricolastr. 2, 38678 Clausthal-Zellderfeld, Germany environment on the welding process are rare. The possible usage of a higher energy density to obtain a larger penetration depth is shown in [7]. This results in a higher process efficiency and a change in the weld metal microstructure due to the faster cooling rates. The aim of this research is to exploit the advantages of the hyperbaric GMAW process. One advantage can be a reduction in the total number of layers, especially for materials with a high thermal conductivity, which show a low penetration during welding.

Furthermore, the reduction of pores while welding aluminium is a key challenge and there are different approaches for pore reduction in the literature [8-10]. One approach for example uses double pulses in pulsed gas metal arc welding to reduce the amount of pores [8]. Ryan et al. show that the manufacturing charge of the wire has an extensive influence on the pore formation [10]. These pores can have a significant influence on the fatigue performance of the material [11]. To generate a beneficial effect on pores, due to a hyperbaric process environment, the shift towards higher values of the solubility of gases in liquids with higher pressure will be utilized [12]. This will narrow the gap between the solubility of hydrogen in solid and liquid aluminium, followed by a reduction of pores.

In addition to the processing of one aluminium alloy, the welding of a copper-alloy will be presented. In both cases, the effect of the elevated ambient pressure on the penetration depth 
and, for aluminium, the influence on the microstructure will be shown. Gas metal arc welding of copper and copper alloys is challenging, due to the high thermal conductivity, so the penetration depth with arc-based welding methods is limited. Thickwalled copper components represent a worst-case scenario due to the increased heat dissipation. Alternative welding methods based on laser or electron beams cannot substitute for GMAW in all cases. Hyperbaric ambient pressure can increase the penetration depth with the same energy input by welding thickwalled copper components. In the following, investigation on the penetration depth of GMA-welded copper in dependence of to the ambient pressure is shown.

\section{Experimental setup}

Initially, the design of the hyperbaric chamber was carried out based on the layout shown in Fig. 1.

The chamber guarantees a constant hyperbaric atmosphere with a maximum ambient pressure of 50 bar. Argon is used as a shielding gas to create an inert atmosphere in the hyperbaric chamber. A special feedthrough, which resists high pressures and ensures a low leakage during welding, feeds the welding wire into the chamber. By using a linear guidance unit, the welding process can be carried out on materials with a maximum height of $20 \mathrm{~mm}$. The online measurement of the voltage and current and the monitoring of the arc length by a highspeed camera during welding lead to a direct analysis of the welding process. Furthermore, the current and the voltage of the welding process have been monitored.

The welding tests were carried out following a statistical design of experiments (DoE). This gives the opportunity to derive a statistical model. The changed variables for the DoE have been the voltage correction for a standard welding characteristic, the ambient pressure and the wire feed speed for bead on plate welds. The variables have been selected so that they can be set directly. The welding speed has been set to 30 $\mathrm{cm} / \mathrm{min}$. The used welding machine was a EWM Alpha Q 551. The voltage corrections shift the characteristic curve of the welding machine to higher or lower voltages for given working points, resulting in a longer or shorter arc when welding under normal conditions. The base material was an AlMg3 plate with a plate thickness of $15 \mathrm{~mm}$. The filler material was a $\mathrm{AlMg} 4,5 \mathrm{MnZr}$ with a diameter of $1.2 \mathrm{~mm}$.

The thickness of the copper plate (Cu-DHP) was $15 \mathrm{~mm}$, and the diameter of the copper filler (CuSn6) metal used is 1 $\mathrm{mm}$. To generate a visual differentiation between the base material and the weld metal, the filler metal is alloyed with $6 \%$ of tin.

The nominal chemical compositions of the used materials are shown in Table 1.

For the determination of the weld microstructure and the penetration, cross-sections have been taken from the weld $50 \mathrm{~mm}$ behind the start of the weld. For the determination of the microstructure, a SEM and an optical microscope Leyca DM 6 with different etched cross-sections have been used.

The pore area fraction has been determined by an optical greyscale threshold analysis on the entire area of the weld seam.

To visualize the grains in the weld metal, the cross-sections have been electrolytically colour etched in according to Baker using at a voltage of $16 \mathrm{~V}$ and a flow rate of $12 \mathrm{l} / \mathrm{min}$. The electrolyte used was $35 \%$ tetrafluoroboric acid at $20{ }^{\circ} \mathrm{C}$ for 20 s. The images were taken using polarized light.

\section{Results}

Below, the results for an aluminium and a copper alloy for hyperbaric welding are shown. First, the results for aluminium are presented.

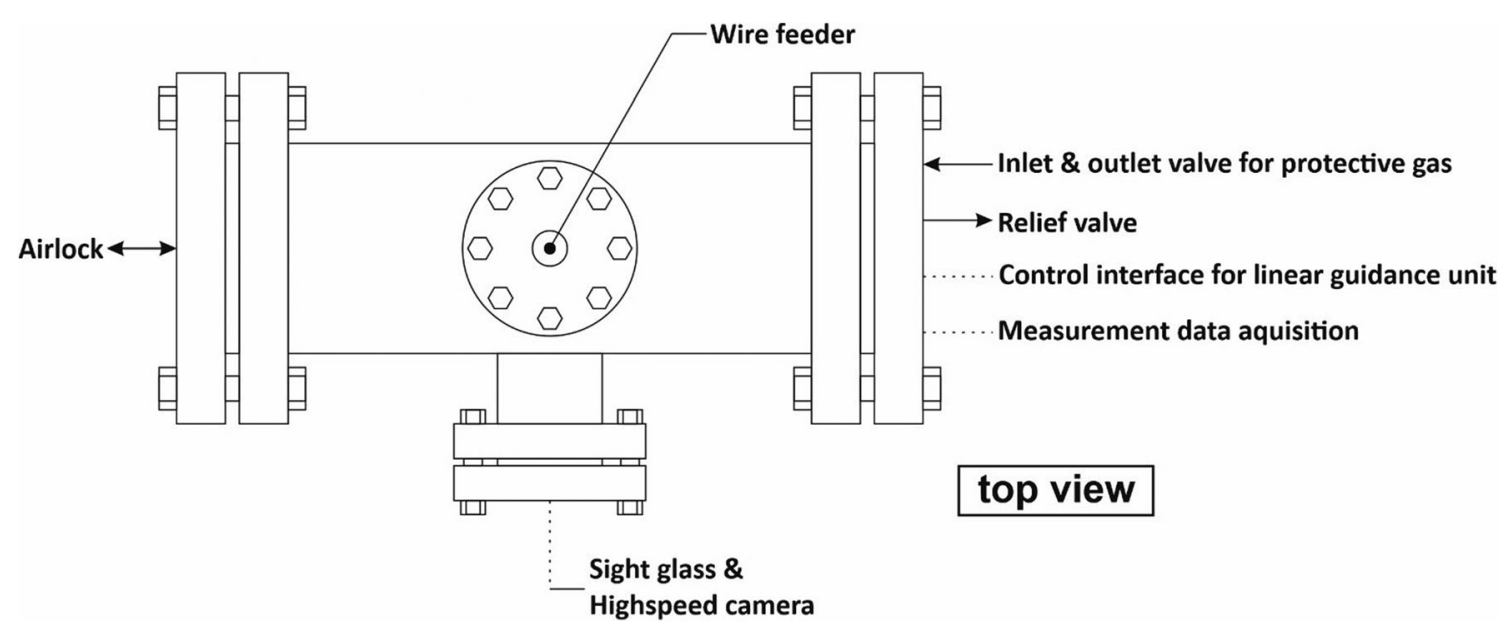

Fig. 1 Test-setup (scheme) 
Table 1 Nominal chemical composition of the used materials

\begin{tabular}{lllllllllll}
\hline Material & $\mathrm{Bal}$ & $\mathrm{Mg}$ & $\mathrm{Sn}$ & $\mathrm{Si}$ & $\mathrm{Mn}$ & $\mathrm{Cr}$ & $\mathrm{Ti}$ & $\mathrm{Zr}$ & $\mathrm{Fe}$ & $\mathrm{P}$ \\
\hline AlMg (base plate) & $\mathrm{Al}$ & $2.6-3.6$ & - & 0.4 & 0.5 & 0.3 & 0.15 & - & 0.4 & - \\
$\begin{array}{l}\text { AlMn4,5MnZr } \\
\quad \text { (wire) }\end{array}$ & $\mathrm{Al}$ & $4.5-5.2$ & - & - & 0.7 & 0.15 & 0.1 & 0.2 & - & - \\
CuSn6 & $\mathrm{Cu}$ & - & $5.5-7.0$ & - & - & - & - & - & - & $0.01-0.4$ \\
Cu-DHP & $>99.9$ & - & - & - & - & - & - & -- & - & $0.015-0.04$ \\
\hline
\end{tabular}

\subsection{Results for aluminium}

The cross-sections of the bead-on-plate aluminium welds show that the shape becomes more finger-like with increasing ambient pressure and the depth of the penetration is significantly increased (Fig. 2). This supports the thesis that an increased energy density of the arc leads to deeper penetration, in accordance with the literature. The pore formation is reduced as well due to the elevated ambient pressure. This can be explained by a higher solubility of gases in liquids with increasing ambient pressure f.e. [12].

In the following, the interrelationship between the ambient pressure and the penetration depth will be shown. The focus here is on the description of process behaviour with a statistical model. Initial, bead-on-plate welding was performed to investigate the process behaviour using different ambient pressures and process parameters.

Here, an implementation of a design of experiments reduces the total number of necessary experimental runs and defines a statistically validated process window. A d-optimal design was used due to the definable process limits and distribution of tests. The wire feed speed, arc length correction and ambient pressure were selected as independent input parameters for the design of experiments. The statistical model can be derived for different output parameters. In the following, the penetration depth is set as the primary output parameter to define the statistically validated process window as shown in Fig. 3 [13]. In addition, the area fraction of pores has been measured and has been taken into account as well (Fig. 7).

The DoE study, shown in Table 1, includes 18 field tests distributed in the process window shown above. The derived statistical model shows that the wire feed speed and the ambient pressure are the primary influence factors for the total penetration depth (Fig. 3). The arc length correction has only a partial influence on the penetration depth. The penetration depth increases only slightly with the arc length correction, so that the arc length correction has only a minor influence on the overall penetration depth.

Furthermore, the model shows that the maximum penetration depth is in mid-level ambient pressure. Higher ambient pressures require also higher voltages to stabilize the arc during the welding process. It is assumed that the power limitation of the welding power source leads to fluctuations in the welding process in conjunction with a buried arc effect and thus to a limited heat input. The fluctuations of the welding current are shown in Fig. 4. The statistical model has a coefficient of determination $\mathrm{R}^{2}$ of 0.94 and a model validity of 0.6 .

The individual measurements of voltage and current while welding with various ambient pressures differ in the wire feed
Fig. 2 Cross-sections for left side: $10 \mathrm{~m} / \mathrm{min}$ wire feed/arc length correction of $0 \mathrm{~V}$ and an ambient pressure of 2 bar; right side: $11.25 \mathrm{~m} / \mathrm{min}$ wire feed/arc length correction of $7.5 \mathrm{~V}$ and an ambient pressure of 16 bar
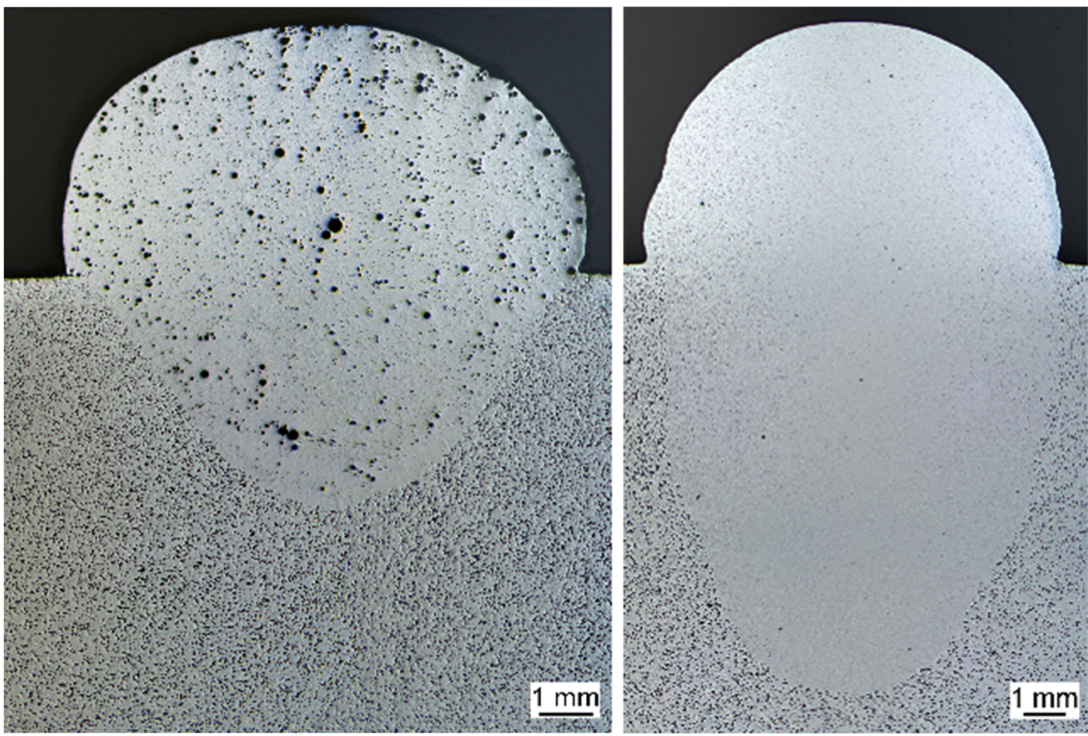


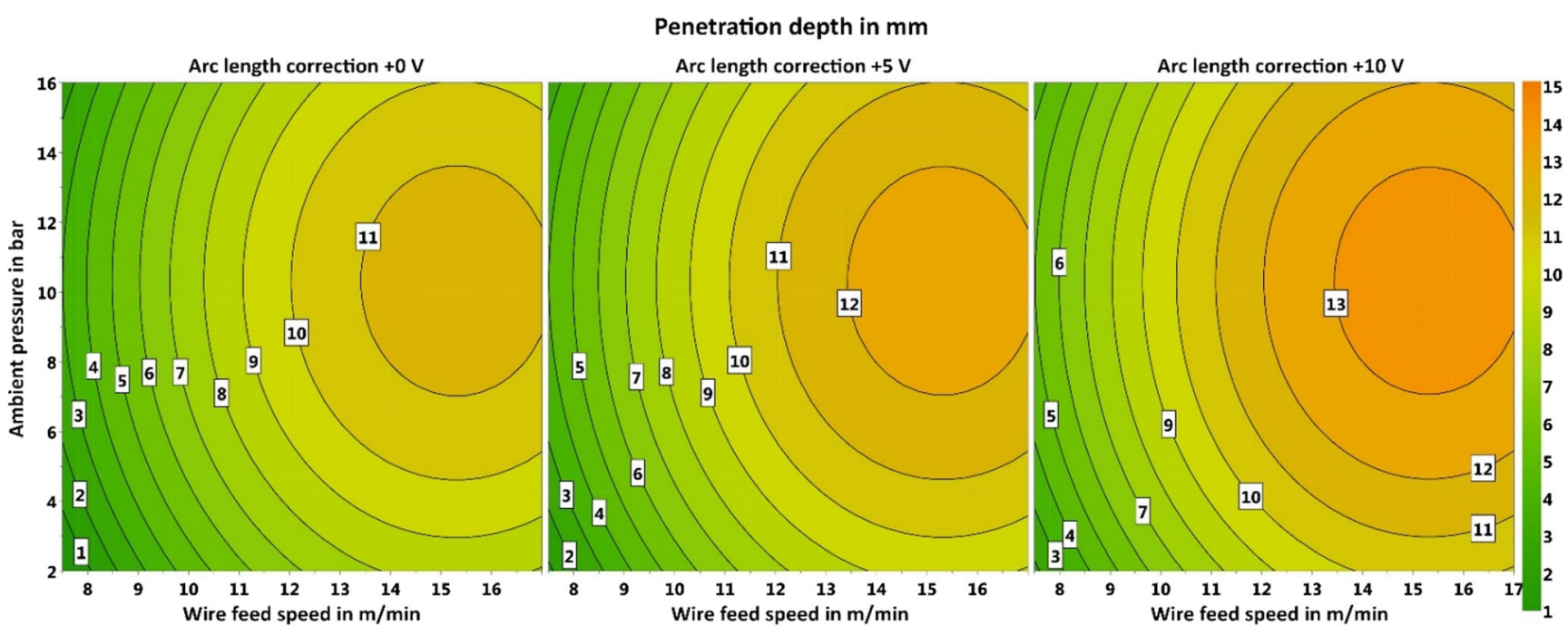

Fig. 3 Statistical model derived from the design of experiments - penetration depthKlicken oder tippen Sie hier, um Text einzugeben
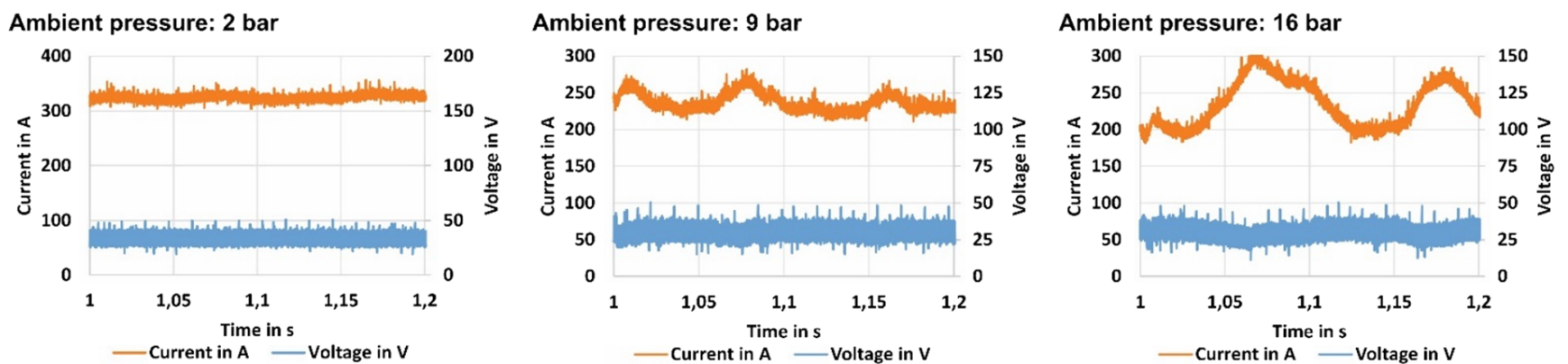

Fig. 4 Measurement of current and voltage at different ambient pressures-Al-alloy

speed. However, it is obvious that with increasing ambient pressure the fluctuations in the welding current become more pronounced. This effect can be explained with the buried arc which is occurring in accordance with higher energy densities [7] (Fig. 5).

The welding power source reaches its power limit and a local maximum penetration depth emerged in the process window. An expansion of the process window is possible by using a welding power source with a higher performance ability. Furthermore, the ambient pressure level can be further increased by simultaneously increasing the voltage. In a further step, the substitution of the existing welding power towards a power source with significant higher maximum voltage is planned.

Fig. 5 Normal and buried arc

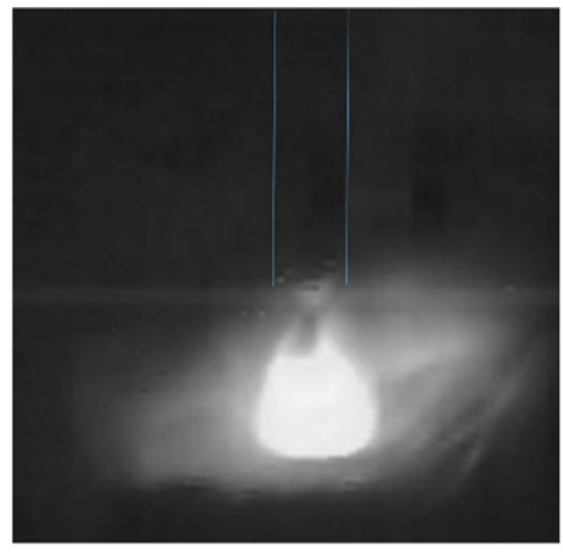

2 bar $14 / s$ Wire feed

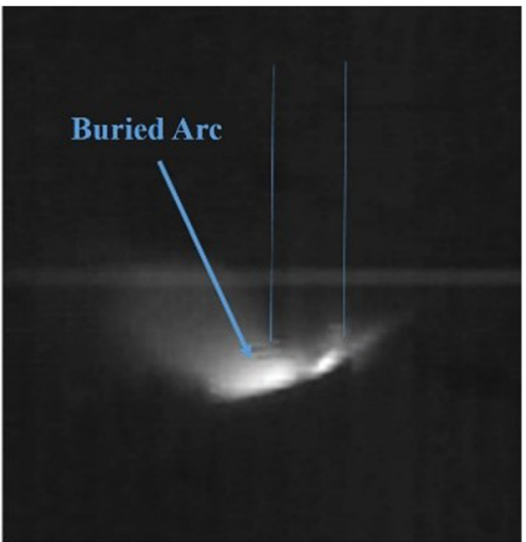

$15 \mathrm{bar} 11 / \mathrm{s}$ Wire feed 
Table 2 Design of experiments with results

\begin{tabular}{llllll}
\hline $\begin{array}{l}\text { Exp } \\
\text { No. }\end{array}$ & $\begin{array}{l}\text { Wire feed in } \\
\text { m/min }\end{array}$ & $\begin{array}{l}\text { Arc length } \\
\text { correction in } \mathrm{V}\end{array}$ & $\begin{array}{l}\text { Ambient pressure } \\
\text { in bar }\end{array}$ & $\begin{array}{l}\text { Weld depth in } \\
\text { mm }\end{array}$ & $\begin{array}{l}\text { Pore area fract. } \\
\text { in \% }\end{array}$ \\
\hline 1 & 7.5 & 10 & 16 & 1.45 & 0.23 \\
2 & 7.5 & 0 & 6.6 & 1.45 & 1.42 \\
3 & 7.5 & 0 & 16 & 1.4 & 0.2 \\
4 & 7.5 & 6.6 & 2 & 2.65 & 4.63 \\
5 & 7.5 & 10 & 2 & 2.85 & 9.81 \\
6 & 10 & 0 & 2 & 4.3 & 4.24 \\
7 & 11.25 & 7.5 & 9 & 9.35 & 0.27 \\
8 & 11.25 & 7.5 & 9 & 11.3 & 0.2 \\
9 & 11.25 & 7.5 & 9 & 10.6 & 0.29 \\
10 & 11.25 & 7.5 & 16 & 10.2 & 0.44 \\
11 & 11.25 & 7.5 & 16 & 9.95 & 0.11 \\
12 & 11.25 & 10 & 9 & 11.65 & 0.24 \\
13 & 14 & 0 & 2 & 7 & 1.15 \\
14 & 15 & 0 & 16 & 10.3 & 0.5 \\
15 & 15 & 7.5 & 9 & 13.75 & 0.81 \\
16 & 15 & 10 & 2 & 8.2 & 0.78 \\
17 & 17 & 0 & 2 & 8.75 & 0.75 \\
18 & 15 & 10 & 16 & 12.45 & 0.05 \\
\hline & & & & & \\
\hline
\end{tabular}

In the cross-sections, the pore area fraction has been determined to prove the thesis that an increased ambient pressure leads to a reduction of pores (Tables 2 and 3 and Fig. 6). Four bead-on-plate seams are shown in Fig. 4. The reduction of pores is visible. The area fractions of pores are given in Tables 2 and 3 and show that an increase of the ambient pressure to 16 bar leads to nearly no pores. The area fraction is only $0.31 \%$ for 16 bar and for 2 bar the area fraction of pores is $4.83 \%$.

Table 3 gives an overview of the used process parameters for welding the specimen from which the cross-sections are taken and shown in Fig. 6.

The derived statistical model for the pore area fraction in the cross-sections in dependence of the varied process parameters (Fig. 7) shows a reduction of pores with increasing ambient pressure for all wire feed rates. The model has a local minimum in the upper left corner for smaller wire feed rates and a high ambient pressure. The arc length correction widens the areas of reduced pores towards higher wire feed and lower ambient pressures. The model has an $\mathrm{R}^{2}$ of 0.9 and a model validity of 0.93 and contains a logarithmic transformation of the pore area fraction.

\subsubsection{Microstructure}

Depending on the ambient pressure and the different cooling, differences in the solidification and microstructure are expected as shown in [14]. These differences can be visualized by the element distribution of the weld metal and barker etching (Figs. 8, 10 and 11). The distribution of Al- and Mg-content in the weld metal is shown in Fig. 8. The element mapping of the test samples was carried out near to the fusion line with linear grain growth. Specimen with an ambient pressure of 2 bar shows a coarse distribution of the Mg-content in the weld metal. With higher ambient pressures, the distribution of $\mathrm{Mg}$-content becomes finely disperse. This gives a strong hint that under elevated ambient pressure smaller and fine disperse distributed eutectic constituents will form. This can be related to a change in the solidification behaviour. Further work on this topic is needed. The orientation of the individual grains of the welds can be visualized with a Barker-etching as shown in Fig. 9.

The weld metal shows columnar grains near to the fusion line. With higher ambient pressure, a disperse distribution of the eutectic constituents increases. Furthermore, the grain size
Table 3 Area fraction of pores for Fig. 4

\begin{tabular}{lllll}
\hline$n$ & Pressure in bar & Porosity in area-\% & Wire feed in $\mathrm{m} / \mathrm{min}$ & Arc length correction in V \\
\hline I & 2 & 4.63 & 7.5 & 6.6 \\
II & 6.6 & 1.42 & 7.5 & 0 \\
III & 9 & 0.27 & 11.25 & 7.5 \\
IV & 16 & 0.11 & 11.25 & 7.5 \\
\hline
\end{tabular}


2 bar

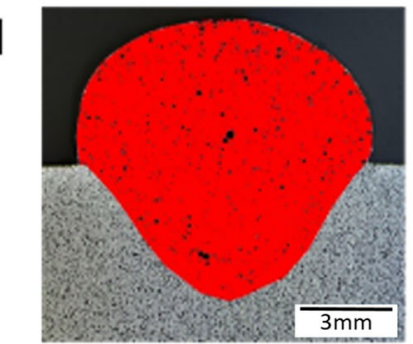

6,6 bar

II

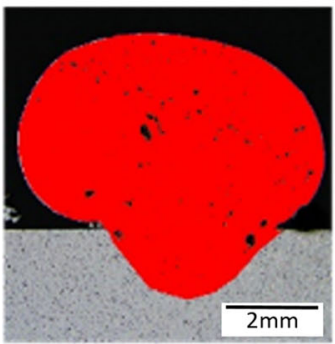

9 bar

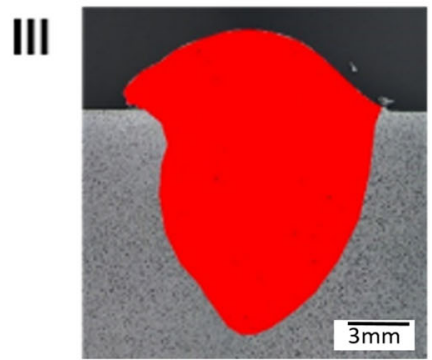

16 bar

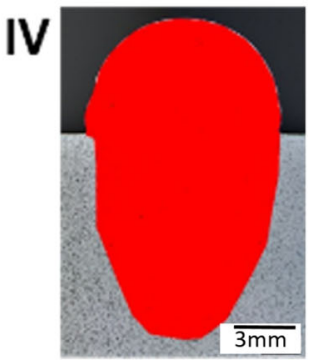

Fig. 6 Pore formation in the welds

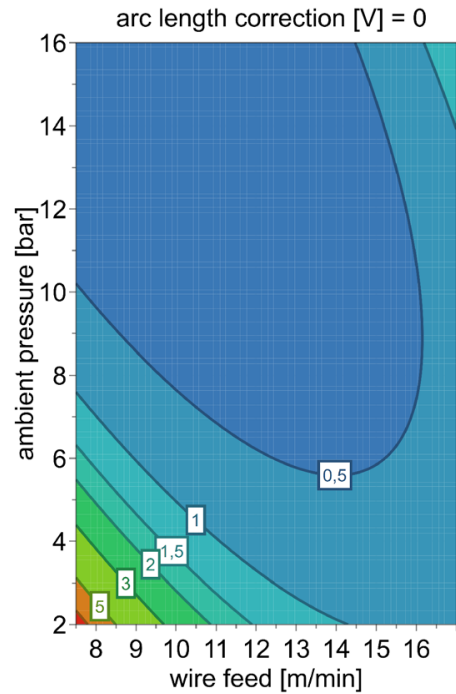

arc length correction [V] = 5

arc length correction $[\mathrm{V}]=10$

Pore area fraction [\%]
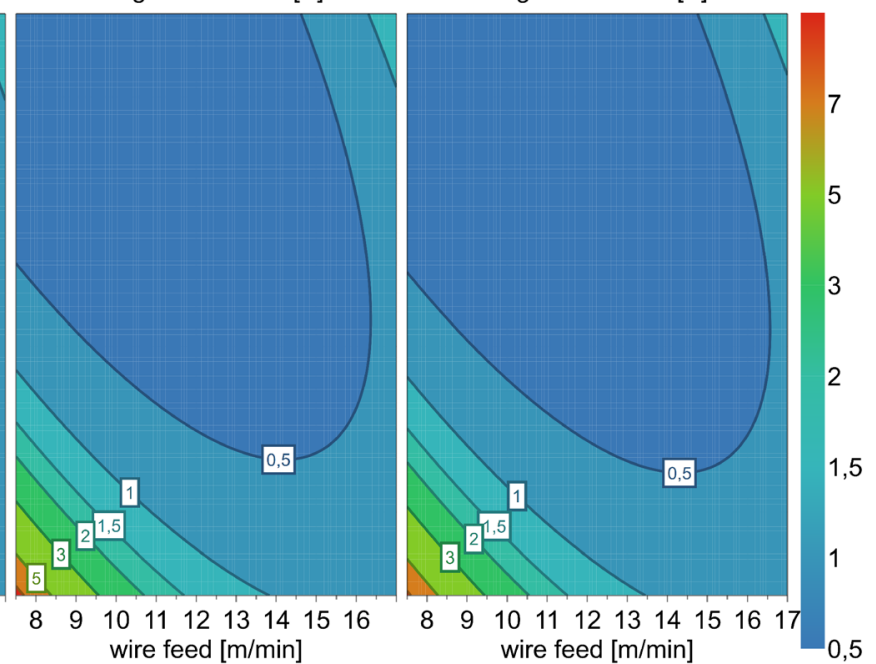

Fig. 7 Statistical model for the pore area fraction in cross-sections

Fig. 8 Element distribution in the weld metal
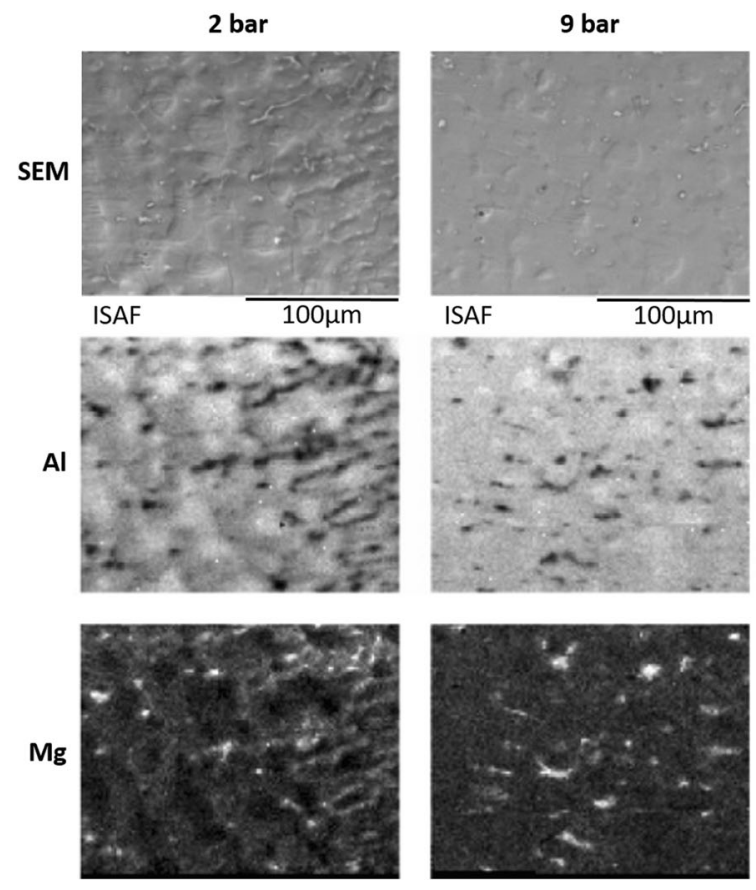


\section{2 bar}

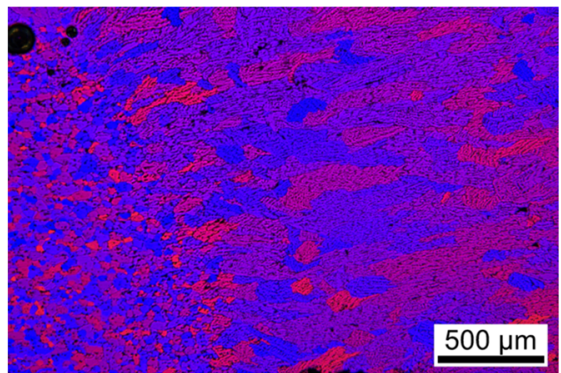

9 bar

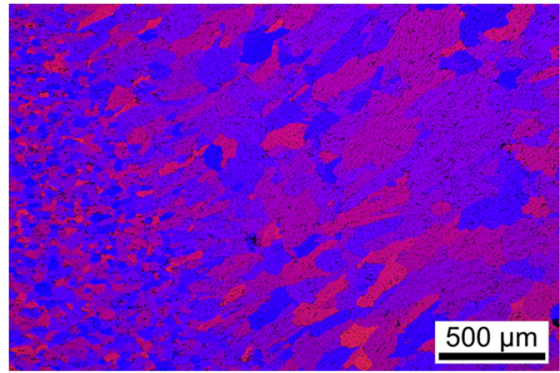

16 bar

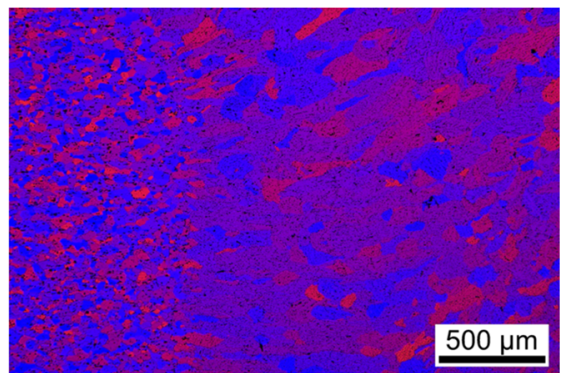

Fig. 9 Barker-etching near to the fusion line for different ambient pressures

Wire feed: $14 \mathrm{~m} / \mathrm{min}$ Arc length correction: $0 \mathrm{~V}$ Ambient pressure: 2 bar

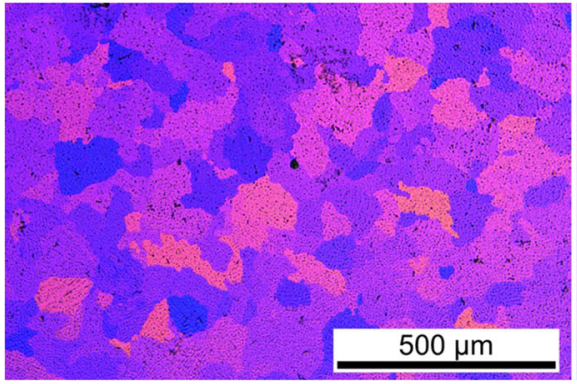

Wire feed: $11,25 \mathrm{~m} / \mathrm{min}$ Arc length correction: 7,5 V Ambient pressure: 9 bar

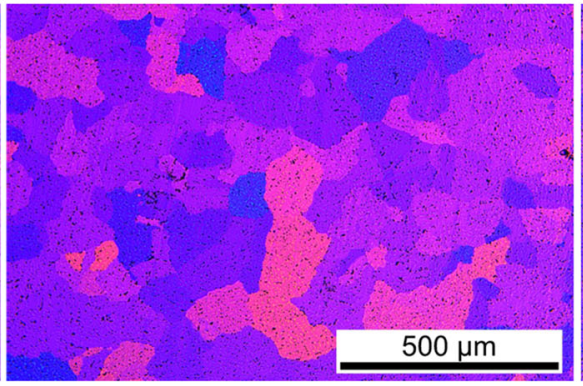

Wire feed: $11,25 \mathrm{~m} / \mathrm{min}$ Arc length correction: 7,5 V Ambient pressure: 16 bar

Fig. 10 Barker-etching in the middle of the weld metal

of the columnar grains is decreasing with higher ambient pressures. In the middle of the weld metal, no significant changes on the grain structure or the grain size have been observed (Fig. 10). Due to the different sizes and energy input of the welding processes, a quantitative evaluation is not leading to proper results and further studies on the solidification and the grain growth have to be done.

\subsection{Results for copper}

Figure 11 shows the current and voltage values over time for different ambient pressures. The penetration depth in subject to the ambient pressure is shown in Figs. 12 and 13. The penetration depth increases with higher ambient pressures under constant welding current and voltage (Figs. 13 and 14). Furthermore, the amount and size of pores have been reduced due to the higher ambient pressure. The absolute heat input between the individual welds is comparable, so that the penetration depth only depends on the ambient pressure in the test welds carried out.

However, there are fluctuations in the welding current at elevated ambient pressures that are similar to the results for aluminium. An ambient pressure of 9 bar results in a stable welding process whereby an ambient pressure of 16 bar shows evidence for a process instability as shown in Fig. 11.
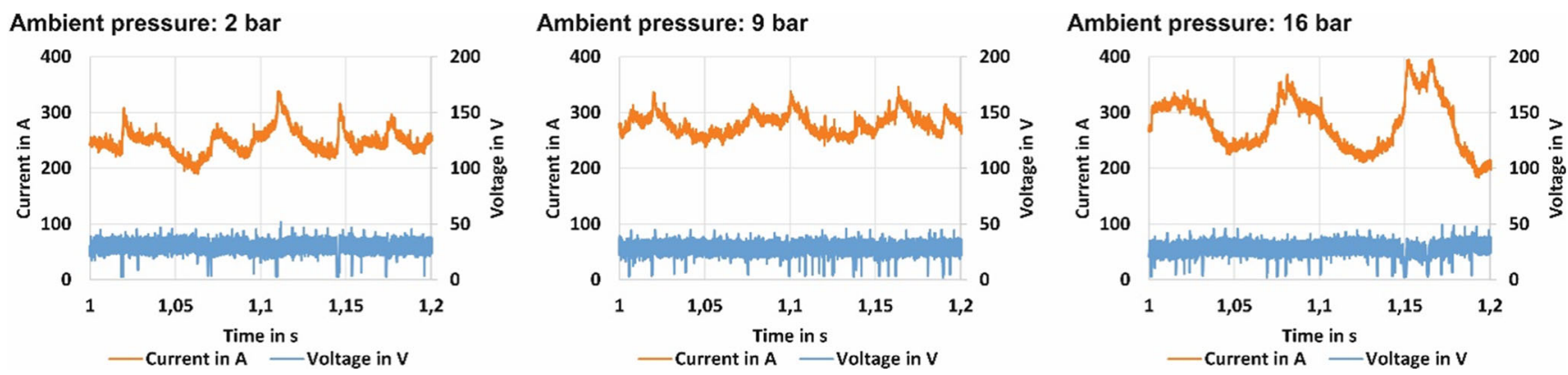

Fig. 11 Measurement of current and voltage by different ambient pressures - copper 

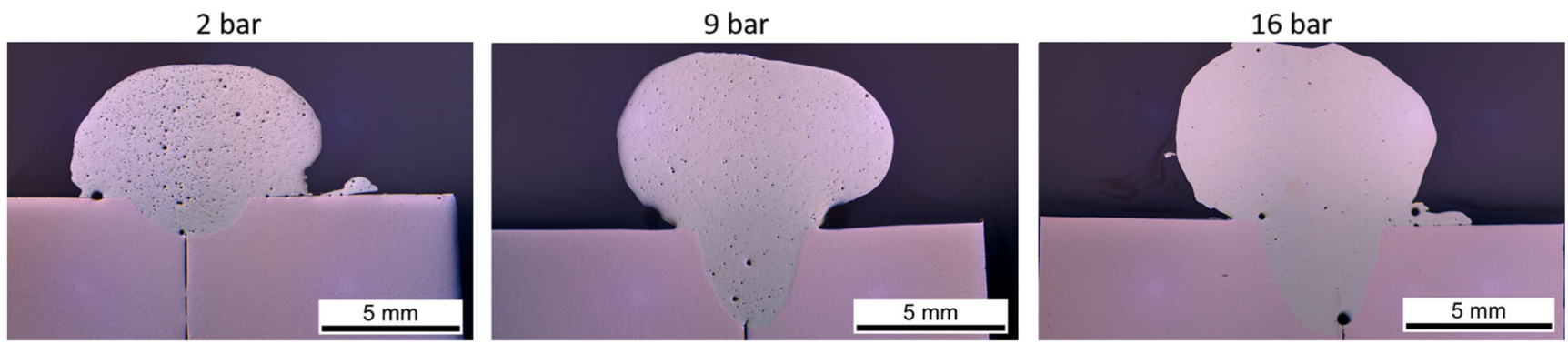

Fig. 12 Cross-section of welded copper under hyperbaric process conditions (270 A/27 V)

Adjusted welding parameters and an increased ambient pressure can increase the welding penetration significantly. This behaviour is supported by the literature. Especially Dutra et al. [7] proposed and showed a significant influence of the energy density on the welding depth. The presented results show a buried arc for higher ambient pressures in the high-speed camera observation and the voltage and current measurements. This both supports the theory that an increased ambient pressure with or without increased welding voltage leads to a higher energy density.

Azar et al. [14] proposed a change in the cooling behaviour due to an increased ambient pressure and this will lead to a different solidification behaviour. The presented results are in line with the proposed changes regarding two parts of the results, firstly due to a change in the precipitation behaviour towards finer disperse precipitates and secondly due to a change of the columnar grain growth near the fusion line. In the middle of the weld metal, no significant differences could be observed. Here, further investigations are needed to clarify the influence of the ambient pressure on the cooling behaviour.

Due to the change in the distribution of the eutectic constituents, a change in the mechanical properties can be expected. These experiments have not been done yet, but are necessary to figure the full potential of an increased ambient pressure for welding of aluminium.
The presented results in reduction of pores give a strong hint that an increased ambient pressure has a beneficial influence on the reduction of pores. However, due to the presented experimental procedure to obtain the area fraction of pores in cross-sections, the results can be considered strong hint. Further investigation with $\mathrm{x}$-ray detection of the pore volume will give a more valid model for pore reduction.

\section{Summary}

The presented experimental results and the derived statistical models show that:

The ambient pressure has a significant influence on

1. The welding depth of the welding process due to a higher energy density

2. The pore formation, due to a change in the solubility of gases

3. The solidification and grain growth, due to a different cooling

Furthermore, for aluminium, a statistical model has been derived for the prediction of the penetration depth. It shows a local maximum in the mid regarding the ambient pressure and the wire feed speed.

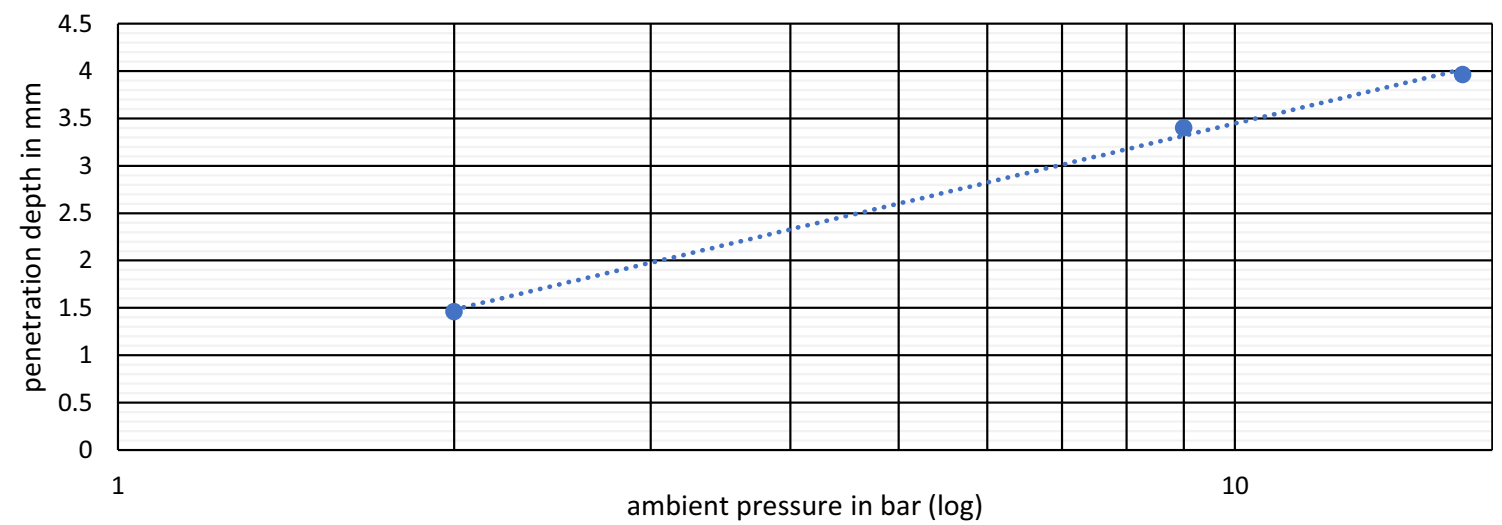

Fig. 13 Penetration depth over ambient pressure for copper 
In addition, a second model for the pore formation in dependence of the given process-variables has been derived. The model shows that an increased ambient pressure can reduce the pore formation.

For copper-alloys, an exponential relationship between the penetration depth and the ambient pressure has been found.

Overall, the results show that a hyperbaric process environment can have a positive influence on the gas metal arc welding process of aluminium and copper alloys.

\section{Outlook}

Further work needs to be done on the mechanical properties of the weld and mechanisms in pore reduction and the influence of diff. Furthermore, other weld seem geometries, f.e. fillet welds will be investigated.

Funding The presented work was funded by the Volkswagen Foundation "Experiment!" framework. Open access funding provided by Open Access funding enabled and organized by Projekt DEAL.

Open Access This article is licensed under a Creative Commons Attribution 4.0 International License, which permits use, sharing, adaptation, distribution and reproduction in any medium or format, as long as you give appropriate credit to the original author(s) and the source, provide a link to the Creative Commons licence, and indicate if changes were made. The images or other third party material in this article are included in the article's Creative Commons licence, unless indicated otherwise in a credit line to the material. If material is not included in the article's Creative Commons licence and your intended use is not permitted by statutory regulation or exceeds the permitted use, you will need to obtain permission directly from the copyright holder. To view a copy of this licence, visit http://creativecommons.org/licenses/by/4.0/.

\section{References}

1. Łabanowski J, Fydrych D, Rogalski G (2008) Underwater welding - a review. Adv Mater Sci 8 https://doi.org/10.2478/v10077-0080040-3

2. Fydrych D, Kozak T (2009) Underwater welded joint properties investigation. Adv Mater Sci 9. https://doi.org/10.2478/v10077009-0016-y

3. Bunaziv I, Aune R, Olden V, Akselsen OM (2019) Dry hyperbaric welding of HSLA steel up to 35 bar ambient pressure with CMT arc mode. Int J Adv Manuf Technol 105:2659-2676. https://doi.org/ 10.1007/s00170-019-04511-6

4. Gyasi EA (2019) Welding processes of metals for offshore environment: underwater welding. Lappeenranta-Lahti University of Technology LUT

5. Klett J, Hecht-Linowitzki V, Grünzel O, Schmidt E., Maier H.J., Hassel T. (2020) Effect of the water depth on the hydrogen content in SMAW wet welded joints. SN Appl Sci 2. https://doi.org/10. 1007/s42452-020-3066-8

6. Tang D, Niu H, Xue L, et al (2017-2017) Study on underwater hyperbaric dry GMAW welding. In: Proceedings of the 2017 7th International Conference on Manufacturing Science and Engineering (ICMSE 2017). Atlantis Press, Paris

7. Dutra JC, Gonçalves e Silva, Henrique R, Riffel KC et al (2020) High-performance GMAW process for deep penetration applications. Welding in the World 64:999-1009. https://doi.org/10. 1007/s40194-020-00889-0

8. da Silva CLM, Scotti A (2006) The influence of double pulse on porosity formation in aluminum GMAW. Journal of Materials Processing Technology 171:366-372. https://doi.org/10.1016/j. jmatprotec.2005.07.008

9. Miao H, Yu G, He X, Li S, Chen X (2017) Comparative study of hybrid laser-MIG leading configuration on porosity in aluminum alloy bead-on-plate welding. Int J Adv Manuf Technol 91:26812688. https://doi.org/10.1007/s00170-016-9917-1

10. Ryan EM, Sabin TJ, Watts JF, Whiting MJ (2018) The influence of build parameters and wire batch on porosity of wire and arc additive manufactured aluminium alloy 2319. Journal of Materials Processing Technology 262:577-584. https://doi.org/10.1016/j. jmatprotec.2018.07.030

11. Texier D, Atmani F, Bocher P, Nadeau F, Chen J, Zedan Y, Vanderesse N, Demers V (2018) Fatigue performances of FSW and GMAW aluminum alloys welded joints: competition between microstructural and structural-contact-fretting crack initiation. International Journal of Fatigue 116:220-233. https://doi.org/10. 1016/j.ijfatigue.2018.06.020

12. White BS, Brearley M et al (1989) Solubility of argon in silicate liquids at high pressure. American Mineralogist 74:513-529

13. Brechelt S, Wiche H, Treutler K et al. (2019) Hyperbares Schweißen von Aluminiumlegierungen. In: 40. Assistentenseminar Fügetechnik: DVS Berichte, Band: 357, 1. Auflage 2019, vol 357. DVS Media GmbH, Düsseldorf

14. Azar AS, Fostervoll H, Akselsen OM Prediction of the thermal cycles in dry hyperbaric GMA welding using partial differential heat transfer equations. In: Conference: 9th International Conference on Trends in Welding Research American Society for Metals

Publisher's note Springer Nature remains neutral with regard to jurisdictional claims in published maps and institutional affiliations. 